\title{
OUTCOME OF PRIMIGRAVIDA WITH HIGH FOETAL HEAD AT TERM OR ONSET OF LABOUR
}

\author{
SAHA MR ${ }^{1}$, YASMINN ${ }^{2}$, CHOWDHURY A ${ }^{3}$, AHMED $\mathrm{S}^{4}$, SWEETY $\mathrm{K}^{5}$, SAHA M
}

\begin{abstract}
Objective: To determine the causes of high foetal head and their relative frequencies in primigravidae presenting at term and to determine the proportion of these patients undergoing lower segment caesarean section or vaginal delivery.

Design: A descriptive study.

Place and duration of study: The study was carried out at Mugda Medical College Hospital from March 2017 to June 2017.

Materials and Methods: A total of 50 primigravidae patients presenting at term and having a single pregnancy were randomly selected. On the basis of history, Physical examination and abdominal ultrasonography, patients having a high foetal head were recognized and their causes documented.

Results: Out of 50 primigravidae, with high foetal head there was foetal malpresentation 17(34\%), Cephalopelvic disproportion 13(26\%), Foetal distress 12(24\%). Lower segment caesarian section was the management of choice in more than half of the patients with high foetal head.

Conclusions: Foetal malpresentation \& Cephalopelvic disproportion were the major cause of high foetal head in this study and lower segment Caesarean section was the mode of delivery in more than half of the patients with high foetal head.
\end{abstract}

Keywords : High foetal head, cephalopelvic disproportion, lower segment caesarean section

J Dhaka Med Coll. 2017; 26(2) : 122-125

\section{Introduction}

A high foetal head in primigravidae at term is regarded as a risk factor for obstructed labour or dystocia ${ }^{1}$ and is indeed major contributor of maternal mortality. Since safe delivery is obstetrician's goal in such cases, it is customary to manage these cases by lower segment caesarean section (LSCS). This has lead to an increased rate of $\mathrm{LSCS}^{2}$ with its financial implications and future family size restriction for the patients.

Studies, however, show that depending upon the cause, many primigravidae with high foetal head can be given a trial of labour and can be successfully delivered vaginally ${ }^{3}$. Finding the cause, therefore, is the first step towards spontaneous or assisted vaginal delivery. The foetal head would remain high whenever there is obstruction in powers, passages and the passenger. This pertains to both bony as well as soft tissue aspects of mother and foetus and includes uterine and extra uterine causes and includes cephalopelvic disproportion (CPD) ${ }^{3}$, foetal malposition ${ }^{4}$, large size of fetus ${ }^{5}$, soft tissue masses in the pelvis such as uterine fibroids, ovarian tumors, placenta previa and even faecal impaction has been reported to obstruct descent of foetus in labour ${ }^{6}$. The frequency of causes of non engaged foetal head varies in different countries according to prevalence of type of pelvis, nutritional status and a trend towards heavier babies.

Keeping in view the prevailing high rates of LSCS in primigravidae with high foetal head at

1. Dr. Mukti Rani Saha, Asst. Prof. (Gynae \& Obs) Mugda Medical College, Dhaka

2. Prof. Dr. Nahid Yasmin, Head, Dept of Gynae \& Obs Mugda Medical College, Dhaka

3. Dr. Afzalunnessa Chowdhury, Prof.( C.C) Shahid Suhwardi Medical College.Dhaka

4. Dr. Shahrin Ahmed, Lecturer, Forensic Medicine, Green Life Medical College, Dhaka

5. Dr. Kamrunnahar Sweety, Jr. Consultant, Mugda Medical College, Dhaka

6. Dr. Madhurma Saha, Registrar, Critical Care Medicine, BIRDEM, Dhaka

Correspondence : Dr. Mukti Rani Saha Asst. Prof. (Gynae \& Obs.), Mugda Medical College, Dhaka, Mob. 01715222508, Email : muktiroy75@gmail.com

Received: 21 July 2017

DOI: http://dx.doi.org/10.3329/jdmc.v26i2.38827 
term, the present study was carried out to document the frequency and causes of high foetal head in primigravidae and to determine the outcome of management, whether LSCS or vaginal for various cau

\section{Materials and Methods}

A total of 50 primigravidae at term, aged 18-34 years and having a singleton pregnancy reporting to Gynae \& Obstetrics department of Mugda Medical College Hospital, were selected by random sampling technique from March 2017 to June 2017. This is a descriptive study.Exclusion criteria: Primigravidae with history of previous uterine surgery or having gross foetal abnormalities, polyhyhydramnios and intrauterine foetal death were excluded from the study. After taking a detailed medical and obstetric history, these patients underwent a thorough physical examination including obstetric examination. Abdominal ultra sonography was then carried out for assessment of foetal biometric parameters and delineating any uterine or ovarian mass. Maternal, foetal and placental causes of high foetal head were assessed on the basis of history, examination and investigations. The patients were then segregated in two groups: those in whom the underlying cause of high foetal head required direct cesarean section and the second in whom a trial of labor was considered. In the second group in whom a trial of labor was undertaken, monitoring of maternal vital signs, her hydration status and uterine contractions were carried out, while foetal monitoring included intermittent auscultation. The over all progress of labor was monitored by a partogram. The mode of delivery, whether, spontaneous or assisted vaginal or abdominal was chosen according to the maternal and foetal progress in labor and the underlying causes were noted.

\section{Results}

Out of 50, high head Primigravidae patients, aged 18-34 years, presenting at term, there was foetal malpresentation 17(34\%), Cephalopelvic disproportion $13(26 \%)$, foetal distress $12(24 \%)$, large foetal size 5(10\%), Placenta preavia $2(4 \%)$ and uterine fibroid $1(2 \%)$. (fig. 1). Percentages of difference outcomes are given in (fig. 2). Among 50 patients, 32 (64\%) were subjected to direct LSCS. These included patients having malpresentation ( $n=9) \operatorname{CPD}(n=13)$, foetal distress $(n=4)$, Large foetal size $(n=3)$, placenta previa $(n=2)$ and lower uterine segment fibroid $(n=1)$. A total of $18(36 \%)$ patients underwent trial of labour. Out of these 18 patients $8(16 \%)$ patients underwent emergency LSCS including all the 5 patients with foetal distress. Two patients having foetal malpresentation and 1 patient in whom no cause for a high foetal head could be determined. Among those 18 patients, another $10(20 \%)$ patients had spontaneous vaginal delivery including 6 patients having foetal malpresentation, another 2 patients having weight more than $4 \mathrm{~kg}$, and 2 patients without any discernable cause.

Table-I

Etiology of nonengaged head

\begin{tabular}{lcc}
\hline Apparent etiology & $\begin{array}{c}\text { Number } \\
(\mathrm{n}-50)\end{array}$ & $\begin{array}{c}\text { Percentage } \\
(\%)\end{array}$ \\
\hline Malpresentation & 17 & $34 \%$ \\
Cephalopelvic & & \\
disproportion & 13 & $26 \%$ \\
Foetal distress & 12 & $24 \%$ \\
Large foetal size & 5 & $10 \%$ \\
Placenta praevia & 2 & $4 \%$ \\
Uterine fibroid & 1 & $2 \%$ \\
\hline
\end{tabular}

Table-II

Mode of delivery

\begin{tabular}{lcc}
\hline Mode of delivery & $\begin{array}{c}\text { Number } \\
\text { (n-50) }\end{array}$ & $\begin{array}{c}\text { Percentage } \\
(\%)\end{array}$ \\
\hline Direct LSCS & 32 & $64 \%$ \\
Spontaneous vaginal & 10 & $20 \%$ \\
delivery & & \\
Emergency LSCS & 8 & $16 \%$ \\
\hline
\end{tabular}




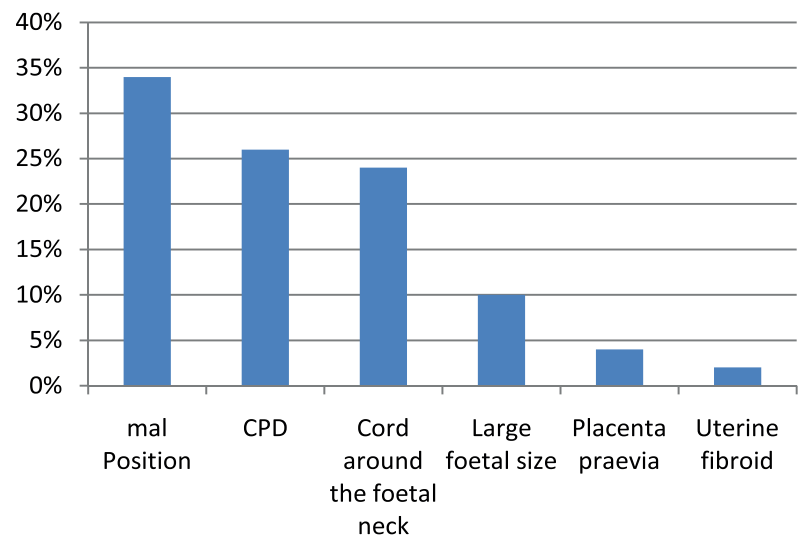

Fig.-1: Percentage of causes of high foetal head at term

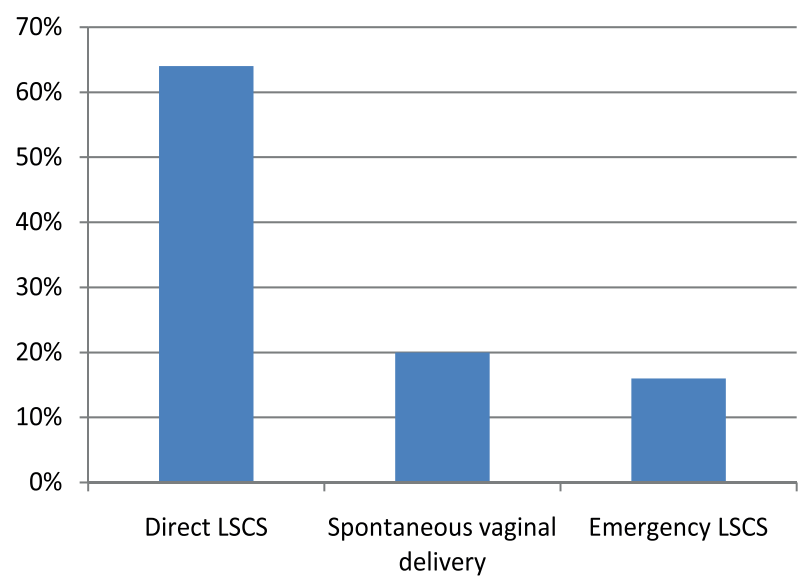

Fig.-2: Percentage of outcome

Maternal morbidity was higher in women with nonengaged head

Table-III

Maternal morbidity

\begin{tabular}{lcc}
\hline Maternal morbidity & $\begin{array}{c}\text { Number } \\
(\mathrm{n}-50)\end{array}$ & $\begin{array}{c}\text { Percentage } \\
(\%)\end{array}$ \\
\hline Perineal tear & 2 & $4 \%$ \\
PPH & 8 & $16 \%$ \\
Wound infection & 7 & $14 \%$ \\
Hospital stay $>2$ days & 12 & $24 \%$ \\
\hline
\end{tabular}

Table-IV

Foetal outcome (Apgar scores at 5 minutes)

\begin{tabular}{lc}
\hline Apgar at 5 mins & $=\mathrm{n}$ \\
\hline $7-10$ & 39 \\
$4-6$ & 8 \\
3 & 3 \\
\hline
\end{tabular}

\section{Discussion}

In the last two decades, the rising rate of LSCS is under critical review. One of the main reasons of this escalation is direct LSCS of primigravidae with nonengaged foetal head at term which is a frequently encountered finding in obstetric practice. In our study, $58 \%$ primigravidae presenting at term had unengaged foetal head. This is supported by similar studies carried out over the past three decades by Weekes and Flynn ${ }^{7}$, Takahashi and Suzuki ${ }^{8}$, Kushtagi 9 and Oiegman et al ${ }^{10}$, who observed high foetal head in $50 \%, 75 \%, 83 \%$ and $69 \%$ of their patients, respectively. Interestingly, all these studies did not observe any significant difference in labour outcomes between nulliparous women with engaged or non engaged foetal head at onset of labour.

The main causes of high foetal head in our study were $\mathrm{CPD}$ and foetal malpresentation. A similar finding is documented by Mokasha FM ${ }^{11}$, Trevino Tamez et al ${ }^{12}$, Bolaji, Meehan FP 13 and Gayam A ${ }^{14}$. These studies concluded that foetal malposition is the most common cause of non engaged foetal head especially in teenage primigravidae. A high incidence of CPD was also noted in this age group. Plausible explanations of these observations were that young pregnant subjects have an inadequately developed small pelvis as compared to the foetal size, to allow normal rotation, adaptation and smooth passage to the foetus. This leads to foetal malposition and CPD. Another five year study at National Maternity Hospital at Dublin observed that persistent occipitoposterior (OP) position $(24 \%)$ and CPD (11\%) were the main causes of high foetal head in primigravidae patients ${ }^{15}$. In our study, persistent OP position was observed in only six primigravidae having high foetal head, whereas other causes of high foetal head like foetal, placenta previa, cord around foetal neck and uterine fibroids occurred with even much less frequency. An important observation of this study was that no cause could be ascertained in 1 subjects.

Out of 50 patients with high foetal head,32 (64\%) patients underwent LSCS while 10(20\%) Patients delivered vaginally when given a safe trial of labor, with satisfactory maternal and foetal outcome. The subjects undergoing LSCS 
included all patients having CPD, placenta previa, patients having umbilical cord around foetal neck, uterine fibroids. This finding is in line with the Mexican study that observed a $45 \%$ LSCS rate in patients with high foetal head. Local studies by Qureishi et al ${ }^{16}$, documented a frequency of 53\% LSCS in these patients was due mainly to CPD and foetal malposition 17 observed a $24 \%$ LSCS rate in primigravidae with high foetal head. These studies also - observed that spontaneous onset of labor in such patients was a predictor of successful normal vaginal delivery and therefore a significant number of operative deliveries could be avoided even in this high risk group of patients by giving them a safe trial of labor. A study by Murphy 18 implied foetal macrosomia (foetal weight $>4 \mathrm{~kg}$ ) and OP -position as risk factors for LSCS, but recommended vaginal delivery in these subjects unless these risk factors were compounded by concurrent CPD.

\section{Conclusions}

Foetal malpresentation \& cepholopelvic disproportion were the major cause of high foetal head in this study and lower segment Cesarian section was the mode of delivery in only $64 \%$ of these high risk subjects.

\section{References}

1. Jafarey SN. Maternal mortality in Pakistan compilation of available data. J Pak Med Assoc 2002; 52: 539-54.

2. Macara LM, Murphy KW. The contribution of dystocia to the cesarian section rate. Am J Obstet Gynecol 1994; 171: 71-7.

3. Lis CK. Analysis of 100 cesarian sections with the indication of cephalopelvic disproportion. Chinese Med J 1995; 30:206-8

4. Sizer AR, Nirmal OM. Occipitoposterior position: association factors and outcome in nulliparas. Obstet Gynae 2000;96:749-52
5. Turner MJ, Rasmussen MJ, Turner JE, Boylan PC, McDonald O, Stronge JM. The influence of birth weight on labor in nulliparas. Obstet Gynecol 1990; 76: $159-63$

6. Smith WP, Mozley PD. Dystocia caused by chronic faecal impaction. J Am Board Fam Pract z1992; 5: 333-4.

7. Weekes AR, Flynn MJ. Engagement of foetal head in primigravidae and its relationship to duration of gestation and time of onset of labor. $\mathrm{Br} \mathrm{J}$ Obstet Gynaecol 1975; 82: 7-11.

8. Takashi K, Suzuki K. Incidence and significance of unengaged fetal head in nulliparas in early labor. Int J Biol Res Pregnancy 1982; 3: 8-9.

9. Khushtagi P. Pattern of descent of fetal head in normal labor. J Indian Med Assoc 1993; 93: 36-9.

10. Diegman EK, Chez RA, Dan Clair WG. Station in early labor in nulliparous women at term. J Nurse Midwifery 1995; 4: 382-5.

11. Mokasha FM. Comparison of pregnancy and labor in teenagers and primigravidae aged $21-25$ years in Transkei. S Afr Med J 1992; 81: 421-3.

12. Trevino Tamez G, Puente GK. Indications for cesarean section: review of 300 cases. Ginecol Obstet Mex 1998; 66: 411-3.

13. Boaji II, Maheen FP. Cesarean section in Galway 1973 through 1987. Eur J Obstet Gynecol 1996; 88: 211 5 .

14. Gayam A. Obstructed labor at a district hospital. Ethiop Med J 2002; 40(1): 11-8.

15. Malone 0, Geary M, Chelmow 0, Stronge J, Boylan P, D' Alton ME. Prolonged labor in nulliparas: lessons from active management of labor. Obstet Gynecol 1996; 88: 211-5.

16. Qureishi NS, Saleem F, Riaz S. Primigravidae with non-engaged fetal head at term: An audit of delivery outcome. Annals KE Med Coll 1999; 5:177-9

17. Najmi RS. An audit of cesarean section carried out in a tertiary care maternity unit. J Coll Physicians Surg Pak 2000; 10(1): 24-6.

18. Murphy OJ, Liebling RE, Verity L, Swingler R, Patel R. Early maternal and neonatal morbidity associated with operative delivery in second stage: a cohort study. Lancet 2001; 358: 1203-7. 